Community-Academic Partnerships in the Community Engagement Literature: A Scoping $\underline{\text { Review }}$

By: Emily Janke, Santos Flores, and Kathleen Edwards

Janke, E., Flores, S., \& Edwards, K. (2021, September 3). Community-Academic Partnerships in the Community Engagement Literature: A Scoping Review.

https://doi.org/10.31219/osf.io/cq5xd

(C) 2021 The Authors. Published under a Creative Commons Attribution 4.0 International License (CC BY 4.0); https://creativecommons.org/licenses/by/4.0/

\begin{abstract}
:
This article contributes a novel dataset mapping the partnership literature in the community engagement field and invites scholars of community-academic partnerships in the community engagement field to participate in the development of scoping reviews as a way to effectively scan extant literature as they seek to build upon or critique it. This scoping review includes key article-level characteristics regarding the representation of community-academic partnerships within 141 published articles from seven peer-reviewed journals in the community engagement field.
\end{abstract}

Keywords: scoping review | systematic review | partnerships | community engagement | community-engaged scholarship

\title{
Article:
}

The dataset for this article is available from CivicLEADS through openICSPR:

Janke, E, Flores, S, \& Edwards, K. (2021). Dataset for "Community-academic partnerships in the community engagement literature: A scoping review". Ann Arbor, MI: Inter-university Consortium for Political and Social Research [distributor]. https://doi.org/10.3886/E146781V2.

$* * *$ Note: Full text of article below 
Authors: Emily M. Janke* (emjanke@uncg.edu), Santos Flores, Kathleen Edwards

Affiliation: University of North Carolina at Greensboro

${ }^{*}$ Corresponding author

\begin{abstract}
This article contributes a novel dataset mapping the partnership literature in the community engagement field and invites scholars of community-academic partnerships in the community engagement field to participate in the development of scoping reviews as a way to effectively scan extant literature as they seek to build upon or critique it. This scoping review includes key article-level characteristics regarding the representation of community-academic partnerships within 141 published articles from seven peer-reviewed journals in the community engagement field.
\end{abstract}

\title{
Keywords
}

Scoping review, systematic review, partnerships, community engagement, community-engaged scholarship 
COMMUNITY-ACADEMIC PARTNERSHIPS IN THE COMMUNITY ENGAGEMENT

LITERATURE: A SCOPING REVIEW

\section{Opportunity Statement}

Community engagement is yet an "emerging field" (Giles, 2019) that has come to present a distinct view and ethos about the role and practice of higher education in and with communities. In the formation of the field, scholars have contributed a new understanding and practice of community-engaged scholarship, most notably, community engagement pedagogy and epistemology (Sandmann et al., 2008). Since the launch of the Michigan Journal of Community Service Learning (MJCSL) in 1994, the first journal in the field, nearly a dozen scholarly, peer-reviewed journals have been initiated as a way for scholars to share research and conceptual scholarship about a range of topics related to community engagement.

Community engagement journals advance the "scholarship on the scholarship of engagement" (Sandmann, 2008, p. 99) as they continue to articulate defining aspects of community engagement including key purposes, practices, processes, and outcomes. Journals in the field publish articles that address many different aspects of community engagement, including pedagogy, epistemology, research methodology and other scholarly approaches, institutional change models, and partnership development and ethics, to name a few.

Commemorating the 20th anniversary of the Journal of Higher Education Outreach and Engagement (JHEOE), the editor of the journal published a book that included previouslypublished articles from JHEOE that had the greatest impact on scholarship and practice. In an effort to frame future-looking conversations by revisiting past scholarship in light of current contexts, the authors of the most impactful articles were invited to revisit, comment on, refute, or to update their earlier writing (Sandmann \& Jones, 2019). Judith Ramaley, a three-time president and foundational leader in the institutionalization of community engagement in higher education, shared her view of the first 20 years of scholarship, reflecting on the changes that must yet be 
COMMUNITY-ACADEMIC PARTNERSHIPS IN THE COMMUNITY ENGAGEMENT

LITERATURE: A SCOPING REVIEW

addressed by scholars of engagement. Ramaley (2019) calls on scholars to re-examine and rearticulate what scholars of the field mean by "community voice" as an aspect of practice and scholarship (p. 257). On the topic of community voice, Ramaley points to increased awareness of and attention to issues of social equity and social justice and especially to communities as intellectual spaces. How is knowledge that resides outside of the disciplines recognized and integrated into academic scholarship? How are the voices of underrepresented, marginalized, and disenfranchised individuals taken into account when we say that we have included community voice as an aspect of our scholarly process?

The call for continued focus on community engagement partnerships echoes earlier calls. For example, Gelmon and colleagues (1998) called the emerging field to develop scholarship that addressed various aspects of partnerships, including:

- the challenge of distinguishing service-learning from community-based clinical training experiences,

- community perspectives of the university and partnerships,

- reciprocity and mutuality in community-university relationships,

- social and economic benefits arising from the community-university partnership,

- benefits for community organizations participating in university partnerships, and

- motivations for universities to respond to community perspectives (p. 97).

Our review of the scholarship shows key aspects of early writings about community engagement partnerships were focused primarily on (a) how to define them differently from other forms of relationships that occur between academic and community-placed or community-focused organizations, (b) the identification of key principles and practices for ethical and effective 
COMMUNITY-ACADEMIC PARTNERSHIPS IN THE COMMUNITY ENGAGEMENT

LITERATURE: A SCOPING REVIEW

community-engagement partnerships, and (c) the description of partnership activities and programs as examples from which others could learn.

Other scholars have suggested that there is a paucity of high quality studies that advance the understanding of how and why partnerships work. As Hart et al. (2009) share of their own experiences looking for articles relevant to establishing community-university partnership services: "It is not that there is a lack of imaginative practical activity... Rather, there is a relative lack of research focused on the processes by which higher education institutions establish community partnerships and how they are sustained" (p. 48). Olszowy Jones and Lee (2017) found a "lack of attention" to community voice in their review of articles published from 20052014 in the Journal of Higher Education Outreach and Engagement (JHEOE) (p. 178). The authors wondered whether the paucity of studies on partnerships was unique to the journal itself, or whether this was true across other community engagement journals as well.

The partnerships section editor of the International Journal of Research on ServiceLearning and Community Engagement (IJRSLCE), Alan Bloomgarden (2017), also lamented that the partnership literature was "woefully thin" (p. 165). He called for the development of robust scholarship focused on the where, how, when, and why community engagement partnerships contribute (or not) to community priorities. Partnerships, he observed, tend to be represented as context or a factor related to student learning and other academic priorities. As a result, readers of the literature tend to get peeks into the nature and structure of partnerships more so than receiving a robust description and assessment of the partnerships themselves and, importantly, the ways in which partnerships serve community-identified priorities.

This article examines and describes a subset of the scholarship of engagement literature: partnerships that occur among academic and community collaborators (herein referred to either 
COMMUNITY-ACADEMIC PARTNERSHIPS IN THE COMMUNITY ENGAGEMENT

LITERATURE: A SCOPING REVIEW

as community engagement partnerships or, simply, partnerships). Our guiding question is: What is the state of the partnership literature in the field of community engagement? Our goal was to curate the literature in which the focus was on the partnership as a key, if not the primary, focus of the article. Therefore, we conducted a scoping review to collect and describe the partnership literature as represented across seven, peer-reviewed, community engagement journals. The result of this effort is the contribution of (a) a scoping review as an emerging research strategy that can help to advance scholarship in the field of community engagement; (b) a novel dataset of all articles that address community engagement partnerships across seven journals in the field; (c) a catalogue with descriptive statistics of key partnership characteristics of the articles curated; and (d) an invitation to other scholars to advance the scholarship of engagement on partnerships by participating in the expansion of this scoping review, to use scoping review techniques shared in this article to address other topics, or to use the scoping review dataset to ask new research questions.

\section{Types of Reviews}

Scoping reviews are relatively new to the cadre of strategies designed to systematically collect, and, to varying degrees, synthesize research on a specific topic (Pham et al., 2014). As the name suggests, a scoping review is a strategy to determine the scope, or coverage, of a body of literature. The effect of conducting such a review is the construction of a map of the literature, which can be used to understand the present landscape, as well the basis for conducting future analyses and research. Because scoping reviews are new to the field of community engagement—we found only one published scoping review, about defining community engagement, in our search (see Beaulieu et al., 2018)—we orient the reader briefly by comparing scoping reviews to two other types of reviews: literature reviews and systematic reviews. 
COMMUNITY-ACADEMIC PARTNERSHIPS IN THE COMMUNITY ENGAGEMENT

LITERATURE: A SCOPING REVIEW

\section{Literature Review}

The most common approach used to bring relevant knowledge to bear on a topic is the literature review. For many, a literature review is a component of a larger study and serves to situate the study with regards to existing knowledge; it entails looking for articles related to the topic of initial research or inquiry. In this way, it demonstrates that one has considered the ideas of others who have published in the same or similar area. In their essay written for graduate students about to embark on dissertation research, Boote and Beile (2005) share the importance of generativity, Shulman's (1999) idea that scholarship and research must build on the scholarship of those whose work has come before. A literature review reports the claims made in existing publications while also critically examining the research methods used to make the claims.

A literature review may also be the focus of a publication. An author may seek to present a comprehensive overview of the knowledge, including substantive findings, inquiry frameworks, and methodologies of a particular topic. For example, Dostilio and colleagues (2017) contributed a comprehensive literature review of community engagement professionals (CEPs) in an effort to establish a "competency model for an emerging field" (book title). Teams of authors thoroughly scanned the literature in the community engagement field to generate a comprehensive list of competencies and personal attributes of CEPs. The findings of the literature review then informed the development of a survey for CEPs to further explore patterns, including gaps, in the literature. As Kowal (2017) writes of the book, "The value of this extensive work lies in its ability to communicate the dimensions of a vast and varied field" (p. 181). The review of the literature can be used to discern the range and prevalence of ideas within a body of literature, and to synthesize the ideas that shape the collective conversation. In our 
COMMUNITY-ACADEMIC PARTNERSHIPS IN THE COMMUNITY ENGAGEMENT

LITERATURE: A SCOPING REVIEW

review across seven journals in the community engagement field, we found no articles offering a comprehensive review of the partnership literature.

\section{Systematic Review}

A second type of review commonly used to synthesize the knowledge generated on a topic (particularly in the health professions) is a systematic review. A systematic review is important for understanding the extant body of work related to a particular intervention so that one may understand, for example, whether there is consensus around best practices or the efficacy of the intervention. An example is Drahota et al.'s (2016) manuscript, "CommunityAcademic Partnerships: A Systematic Review of the State of the Literature and Recommendations for Further Research." The team of ten authors reviewed literature across multiple disciplines and major academic databases (e.g., ProQuest, ERIC, PubMed) to identify the most common influences that facilitate or hinder community-academic partnerships (their term). The authors noted that while the amount of published literature on collaborative groups has increased dramatically in recent years, it still lacks consensus and systemic review" (p. 167). They sought all systematic evaluations of the collaborative process among partnerships that (a) included at least one academic and at least one community stakeholder, (b) have been peerreviewed, and (c) written in English. Unlike a literature review, which is often undertaken by a single scholar and includes only those articles most germane to the study, scholars participating in this systematic review sorted through the titles and abstracts of 1,332 articles to then complete a full text review of 630 articles in order to find the 50 articles that ultimately met the criteria for inclusion in their study. Their aim was to collate empirical evaluation evidence from a relatively smaller number of studies pertaining to their focused research question. The team used an a 
COMMUNITY-ACADEMIC PARTNERSHIPS IN THE COMMUNITY ENGAGEMENT

LITERATURE: A SCOPING REVIEW

priori protocol, which was updated iteratively during the systematic review, as well as strategies

to ensure consensus on the issue of whether they used an objective evaluation method.

\section{Scoping Review}

A third type of review, and the method used in this manuscript, is a scoping review.

Alternately, scoping reviews have also been called "mapping reviews" because they "map the key concepts that underpin a field of research, [additionally they] clarify working definitions, and/or the conceptual boundaries of a topic" (Joanna Briggs Institute [JBI], 2015, 11.1.1).

Scoping reviews are most appropriate to address the following six purposes:

- to identify the types of available evidence in a given field;

- to clarify key concepts/definitions in the literature;

- to examine how research is conducted on a certain topic or field;

- to identify key characteristics or factors related to a concept;

- as a precursor to a systematic review; or to

- to identify and analyze knowledge gaps (Munn et al., 2018).

First described by Arksey and O'Malley in 2005, scoping reviews have been precisely refined to the point that there are now stepwise protocols for both conducting and writing about scoping reviews (see Peters et al., 2020; Pham et al., 2014; Tricco et al., 2016). The PRISMA-ScR (Preferred Reporting Items for Systematic Assessments - Scoping Reviews) checklist is one such resource designed to help increase consistency of scoping reviews (Tricco et al., 2016).

In this section we have defined three similar yet unique methods for reviewing available literature about a topic: literature review, systematic review, and scoping review. The purpose of this effort is so readers, now able to distinguish between the three methods, can make more informed decisions about what sort of method will best serve their future research at different 
COMMUNITY-ACADEMIC PARTNERSHIPS IN THE COMMUNITY ENGAGEMENT

LITERATURE: A SCOPING REVIEW

times. For a deeper description of the defining characteristics of traditional literature reviews, scoping reviews, and systematic reviews, we encourage readers to review Munn et al. (2018).

Because scoping reviews are a new technique and born in the health professions, we found only one scoping review on the topic of community engagement. The scoping review included 48 articles with the aim to clarify the definition of engaged scholarship. Their results presented an article-level review of the values, principles, and processes of partnerships put forward in the literature. Values included social justice and citizenship, and principles included high-quality scholarship, reciprocity, identified community needs, boundary-crossing, and democratization of knowledge. They presented an engaged scholarship schema and defined engaged scholarship "as a true academic posture, rooted in values of social justice and citizenship, that prompts academics and universities, in their roles of teaching, research, and service to society, to work in ways that will build mutually beneficial and reciprocal bridges between university activity and civil society" (p. 12).

Systematic and scoping reviews are common within the health sciences (Pham et al., 2014) but have not yet found their way into the literature of the community engagement field. Through previous publications (e.g., Bringle et al., 2013), scholars have demonstrated great benefit by bringing theory and research from cognate areas to the field of community engagement. Our scoping review about community-academic partnerships may serve as an example of the usefulness of applying new research methods to community engagement topics.

\section{Community Engagement Partnership Scoping Review}

This study did not start out as a scoping review, but we ended up conducting one out of necessity. Initially we wanted to develop a dataset consisting of manuscripts that would allow us to pursue a specific research question: what types of conflict occur within community 
COMMUNITY-ACADEMIC PARTNERSHIPS IN THE COMMUNITY ENGAGEMENT

LITERATURE: A SCOPING REVIEW

engagement partnerships? We wished to bring theories developed in the conflict and peace

studies field into the community engagement field as a way to help increase competence and confidence of community engagement professions in this area of work (Janke \& Dumlao, 2019).

Our first step was to identify articles in the community engagement field that could help one understand community-academic partnerships, specifically why and how they do and do not work. Our interests were practical. To interrogate the literature in order to identify the presence of conflict and conflict management practices among community engagement partners, we needed to be able to (a) identify and cull partnership studies from the broader community engagement literature, (b) sort the articles according to various partnership types so that we could understand the varied characteristics and contexts of the partnerships, and (c) examine how various levels and aspects of conflict were or were not addressed in the literature. We faced several challenges.

The first challenge was identifying partnerships articles within the community engagement literature. Broadly, we attempted to identify all articles that could be used to tell us how and why partnerships work. While some articles use the partnership as the unit of analysis or the object of inquiry, more often, partnerships are included in a limited and ancillary way. For example, authors may describe aspects of the partnership, such as whether it was part of a service learning course or an international service project - as a factor of or in service to other goals, such as student learning and development, completing a research project, or fulfilling an institutional service mission (Bloomgarden, 2017). In such articles, we found that partnerships tended to be described poorly and without important details, and the "lessons learned" tended to be offered in anecdotal ways that were not grounded in theory or connected to extant scholarship. 
COMMUNITY-ACADEMIC PARTNERSHIPS IN THE COMMUNITY ENGAGEMENT

LITERATURE: A SCOPING REVIEW

The second challenge was inconsistency of the information shared about partnerships and the difficulty of comparing "apples to apples" across different types of partnerships. We wanted to know: how does conflict relate to the type of partnerships? Authors and editors tend to apply the term partnership to a wide array of relationships between and among individuals, groups, and organizations as well as in reference to varying types of formal and informal agreements (Bringle et al., 2012; Dumlao \& Janke, 2012). Since Cruz and Giles (2000) called for scholars to advance understanding of service learning partnerships using the partnership itself as the unit of analysis, the body of scholarship related to partnerships has increased, yet has continued treating all partnerships as though they are essentially the same, applying common guidance, expectations, and principles to all. We needed a map so that we could begin to purposefully sample the literature for a focused research project on the subtopic of conflict in community-academic partnerships.

The desire to create a scoping review to then allow for subsequent research studies is consistent with Tricco et al.'s (2016) finding: the three most common reasons for conducting a scoping review were to explore the breadth or extent of the literature, map and summarize the evidence, and inform future research. In pursuing our goal, we learned about the value of scoping reviews in and of themselves - as a way to map the literature in the particular area of partnerships - and also to advance the quality and comprehensiveness of future research that builds upon extant literature. The scoping review is, itself, a contribution to the field.

Therefore, this is not a literature review in which we attempt to synthesize the lessons learned across a selection of articles as the foundation upon which to build an investigation or inquiry; we present a scoping review in which we comprehensively curate and describe key characteristics of manuscripts in which the authors share information or reflection about 
COMMUNITY-ACADEMIC PARTNERSHIPS IN THE COMMUNITY ENGAGEMENT

LITERATURE: A SCOPING REVIEW

community-academic partnerships in ways that might help others to understand how, why, or towards what ends community and academic partners engage with each other. The presentation of this scoping review follows the standard PRISMA format. Because our dual purposes of this article are to advance the understanding of how scoping reviews are conducted and to actually conduct a scoping review, we include descriptions of what is expected per the PRISMA-ScR process.

\section{Purpose and Guiding Questions}

The purpose of this study was to curate and describe the partnership literature in the community engagement field in order to advance partnership research and practice. Our guiding question was: What is the state of the partnership literature in the field of community

engagement? Our goal was to identify and describe key characteristics of that literature at the article level.

\section{Methodology}

A key characteristic of scoping reviews is a thick description of the methods, which aligns with a purpose of scoping reviews to be transparent and reproducible. Best practices of scoping reviews include that they:

- are informed by an a priori protocol,

- are systematic and often include exhaustive searching for information,

- aim to be transparent and reproducible,

- include steps to reduce error and increase reliability (such as the inclusion of multiple reviewers), and

- ensure data is extracted and presented in a structured way (Munn et al., 2018). 
COMMUNITY-ACADEMIC PARTNERSHIPS IN THE COMMUNITY ENGAGEMENT

LITERATURE: A SCOPING REVIEW

The methodology for this scoping review was based on the framework outlined by Arksey and O'Malley (2005) and further refined and updated by Peters et al. (2020) in the JBI Manual for Evidence Synthesis. Because these two sources come from the health sciences and were focused on health topics, which is true for the majority of scoping reviews (Pham et al., 2014), we also looked to the example of a scoping review of physical education teacher satisfaction provided by Richards et al. (2017). Hemphill also provided guidance and feedback on our process. This study does not meet criteria for human subjects research so institutional review board approval was not needed.

\section{Protocol}

We developed our protocol through an iterative process wherein the reviewers routinely discussed the goals of the review in order to ensure that we were establishing appropriate and useful criteria for inclusion and exclusion of articles. Figure 1 reflects the process for searching and selecting the manuscripts included in this scoping review. 
COMMUNITY-ACADEMIC PARTNERSHIPS IN THE COMMUNITY ENGAGEMENT

LITERATURE: A SCOPING REVIEW

Figure 1: Flow chart of the review and data collection

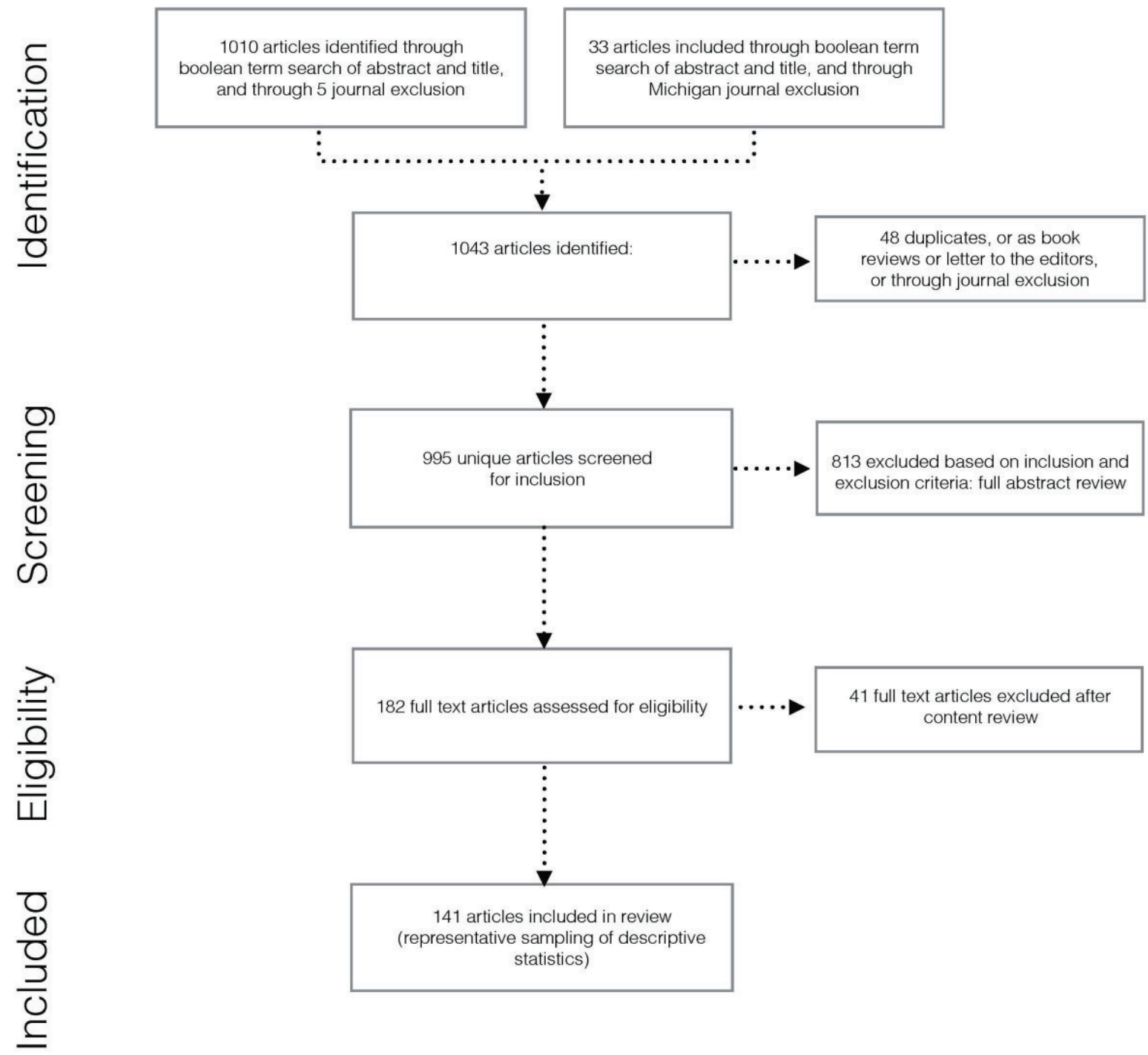

Identification

We used a three-step search strategy as recommended in all JBI (2015) types of reviews.

The first step is an initial limited search of at least four online databases relevant to the topic.

Our initial search was conducted in Education Source, ProQuest, Directory of Open Access

Journals, and Academic Search Complete. 
COMMUNITY-ACADEMIC PARTNERSHIPS IN THE COMMUNITY ENGAGEMENT

LITERATURE: A SCOPING REVIEW

Though not included in Image 1, a key takeaway from our pilot process was the importance of narrowing the journals for inclusion, rather than searching more broadly. It is important to balance feasibility with breadth and comprehensiveness of the scoping process given the volume of articles a search may yield (Levac et al., 2010, pp. 4-8). We found that ultimately it was useful to use two terms — relationship and partnership — and portions of those terms (e.g., relat* and partner*) to identify appropriate articles. Prior to this, we conducted an initial search using the term "partnership" in two databases, which revealed 472,424 articles. We tried again, limiting the keywords to the Boolean terms partner* and relat*, which yielded a still massive 7,319 articles. Next, we added the inclusion and exclusion criteria of (a) peer review, (b) no books, and (c) no reports from web searches, which yielded 6,197 articles. Finally, we chose to limit our term search to the title or abstract only, and still, the number was far too large for our team to feasibly sort through. Further, we realized that the terms were too general as to be useful for locating the types of partnership studies we were seeking.

Ultimately, we decided to limit our search eligibility to articles in seven journals. Scoping reviews are time and resource intensive because they require researchers, working in teams for inter-coder reliability, to read and assess hundreds of abstracts and, later, potentially hundreds of full articles in order to precisely attribute key characteristics. This scoping review, for example, required 995 abstract reviews, and 182 full text reviews. This is the first scoping review of its kind in the field, and as such, provides a pilot of sorts. The development of the strategy to curate articles, as well as to characterize and categorize them, undoubtedly will be refined in future iterations. We offer discussion of future considerations further in this article, which may contribute to these refinements. 
COMMUNITY-ACADEMIC PARTNERSHIPS IN THE COMMUNITY ENGAGEMENT

LITERATURE: A SCOPING REVIEW

We sought to include journals that specifically publish on the scholarship of engagement or community-engaged scholarship. These journals were represented at a panel of "leading SLCE journals" at the International Conference for Research on Service-Learning and Community Engagement (2019) and on the Campus Compact's Community Partnerships Knowledge Hub (n.d.). We used the Carnegie Foundation for the Advancement of Teaching's definition of community engagement: "The collaboration between institutions of higher education and their larger communities (local, regional/state, national, global) for the mutually beneficial exchange of knowledge and resources in a context of partnership and reciprocity” (Carnegie, "Defining community engagement," n.d.). The criteria for limiting our selection to certain journals were that these journals' primary focus is the topic of community engagement in higher education, as stated in their missions. To provide some diversity of journals to help us in this first effort to establish article-level categories and attributes of the partnership literature, we included one journal that is jointly edited and managed by Australian and American scholars, as well as one that focuses on service-learning in the field of engineering. We acknowledge that other journals also publish the scholarship of community engagement as their primary focus, or as one aspect of a broader mission or field and encourage future scoping reviews to include articles from these journals. The seven journals in our scoping review include:

- Gateways: International Journal of Community Research and Engagement (Gateways),

- International Journal of Research on Service-Learning and Community Engagement (IJRSLCE),

- International Journal for Service Learning in Engineering (IJSLE),

- Journal of Higher Education Outreach \& Engagement (JHEOE),

- Journal of Community Engagement \& Scholarship (JCES), 
COMMUNITY-ACADEMIC PARTNERSHIPS IN THE COMMUNITY ENGAGEMENT

LITERATURE: A SCOPING REVIEW

- Michigan Journal of Community Service Learning (MJCSL), and

- Partnerships: A Journal of Service Learning \& Civic Engagement (Partnerships).

Limiting to seven journals in the community engagement field served our study well: Ultimately, we were interested in specifically understanding the lessons learned about a certain type of partnership — a community-engaged, community-academic partnership. Researchers of future scoping reviews might choose to widen the number of journals or type of scholarship included, however, it is important to note that scoping review practices have not yet been developed for expressions of knowledge other than peer-reviewed journal articles. Other expressions and modes of knowledge of community engagement partnerships certainly exist in non-peer review formats as well as in non-textual and non-digitized artifacts.

The second step was to identify the articles within the seven journals. Our search using the root Boolean terms relat* and partner* yielded the greatest number of relevant and fewest number of irrelevant articles (we had also tried relat* OR partner* to less success and efficiency). We limited the search to the abstracts rather than full text. However, because the search platform used for the Michigan Journal of Community Service Learning does not allow one to search abstracts according to our protocol, we used a collated set of abstracts sent by the journal editor (upon request) and searched that document. Our rationale was that if an article is discussing a community-academic partnership, then it would be difficult to convey the focus of that topic in the abstract without also using these root terms. In our search, we included all articles written from the start of the publication until May 2020. Searching the seven journals only, we identified 1043 articles for review, after removing 48 articles that were duplicates, book reviews, or letters to the editor. For additional information about our methods, please contact the lead author. 
COMMUNITY-ACADEMIC PARTNERSHIPS IN THE COMMUNITY ENGAGEMENT

LITERATURE: A SCOPING REVIEW

\section{Screening}

The next step was to screen the 995 articles based on a full abstract review. Two reviewers read through all article abstracts to determine whether they met our goal: Does this article tell us something about community-academic partnerships? Because we were interested in how partnerships work, we were also interested in only those articles that used the partnership as an area of focus or a unit of analysis. Questions that guided this process were: Is there a description of who was involved in the partnership? Is there a description of processes or the results of the partnership work? Based on this manual review of the abstracts, we excluded a further 813 .

\section{Eligibility}

The final step examined the remaining 182 articles in a full text review. Two authors conducted an initial review of the full text articles and identified 41 that did not meet our initial criteria. There was concordance during this process. Articles that received split decisions or that met only some of the inclusion criteria were discussed to reach consensus with the third reviewer. This process resulted in 141 articles included in this study. See the appendix for the 141 articles included, with their assigned characteristics.

\section{Data Charting}

The data extraction process, also referred to as "data charting," was developed and iteratively refined during the full text reviews of the 182 manuscripts by two reviewers and finalized with the inclusion of a third reviewer. They were informed by the types of information one might need to map the literature with regards to the scope of scholarship and the types of evidence used by scholars, as stated in our purpose. We read articles and charted data along eight categories. The authors discussed any discrepancies until they reached consensus. This helped to 


\section{COMMUNITY-ACADEMIC PARTNERSHIPS IN THE COMMUNITY ENGAGEMENT LITERATURE: A SCOPING REVIEW}

clarify and refine the definition and description of the categories and characteristics in the Codebook (Table 1).

Table 1. Codebook

\begin{tabular}{l|l|l|}
\hline Category & \multicolumn{1}{c}{ Characteristic } & Definition/Description \\
\hline $\begin{array}{l}\text { Source of Partnership } \\
\text { Information }\end{array}$ & -- & $\begin{array}{l}\text { Examines whether the ideas about partnerships are presented } \\
\text { using a real life and specific example of a partnership, or } \\
\text { whether the ideas are independent or separate from any real life } \\
\text { and specific partnership identified in the article. }\end{array}$ \\
& &
\end{tabular}

Actual The author presents thoughts about partnerships that are based on actual, real life and specific partnerships that are described in the manuscript.

Idea The author expresses thoughts about partnerships that are based on ideas, principles, practices, concepts, theories, or other types of abstractions on the topic of partnerships and without presentation of any actual partnership.

\begin{tabular}{l|l}
\hline Authors' Scholarly & - \\
Approach & \\
& Qualitative
\end{tabular}
Scholarly approaches used by author(s) to develop the thoughts
presented in the manuscript.

The author collects data (usually non-numerical) through firsthand experience to address questions about concepts, opinions/perspectives, and experiences. Data are typically gained through interviews, questionnaires, focus groups, participant observation, documents, and artifacts.
Quantitative
The author collects and analyzes numerical data to quantify a collection and statistically analyze data using a deductive approach to test hypotheses.

Mixed Methods The research process used in the article included both qualitative and quantitative methods.

Indigenous or

Decolonial

Program

Evaluation
The authors (identify as indigenous and) use approaches that recognize indigenous communities develop shared ways of knowing guided by how they view the world, themselves, and the connection between the two. Part of indigenous knowledge, then, is a combination of the reflection of and resistance to colonization in various realms. Those engaging in indigenous research reflect on who owns, designs, interprets, reports, and ultimately benefits from the research process and products (Smith, 2012).

The author presents a systematic method for collecting, analyzing, and using information to answer questions about projects, policies and programs, particularly about their effectiveness and efficiency. 


\section{COMMUNITY-ACADEMIC PARTNERSHIPS IN THE COMMUNITY ENGAGEMENT LITERATURE: A SCOPING REVIEW}

\begin{tabular}{ll}
\multicolumn{1}{l}{$\begin{array}{l}\text { Conceptual } \\
\begin{array}{l}\text { Project or } \\
\text { Program } \\
\text { Description }\end{array}\end{array}$} & $\begin{array}{l}\text { The author present observations and analysis related to abstract } \\
\text { concepts or ideas. } \\
\text { and does not describe theoretical or conceptual frameworks, } \\
\text { methodology, or research methods. }\end{array}$ \\
\hline Author's Positionality & $\begin{array}{l}\text { The author's relationship to the partnership (if actually } \\
\text { experienced and specifically identified) presented in the } \\
\text { manuscript. }\end{array}$ \\
Direct & $\begin{array}{l}\text { One or more of the authors is/are involved in the partnership } \\
\text { activity described. }\end{array}$ \\
Indirect & $\begin{array}{l}\text { None of the authors are involved in the partnership activity } \\
\text { described. }\end{array}$
\end{tabular}

N/A The manuscript is written as a thought piece in which there is no actual partnership being described.

\begin{tabular}{l|l}
$\begin{array}{l}\text { Community Partner } \\
\text { Positionality }\end{array}$ & $\begin{array}{l}\text { The community partners' voices are represented by their ow } \\
\text { contributions to the writing of the article, or by direct quo } \\
\text { their utterances or writings. }\end{array}$ \\
Co-author & $\begin{array}{l}\text { Community partners listed as an author of the manuscript } \\
\text { Direct quotes }\end{array}$ \\
$\begin{array}{l}\text { Community partners are directly quoted and cited in the } \\
\text { manuscript. }\end{array}$
\end{tabular}

Not evident Insufficient information was provided to determine, how, if at all, community partners' voices were included, either as co-authors or as directly quoted and cited in the manuscript. Articles that summarized community partner voice in aggregate, but did not provide direct quotes, are included in this category.

$\begin{aligned} & \text { Partner Organizational } \\ & \text { Type }\end{aligned}$

The types of formal, informal groups, and organizations to which partners' represent in their partnership work.

K-12 Community partner includes at least one of these populations: schools (as an organization), or teachers, students, parents, or staff affiliated with a kindergarten through high school (i.e., K-12).

Nonprofit An organization that is registered as having not-for-profit status.

Informal A group of people who have common interests who coordinate Organization activities and networks to achieve shared goals.

Government A level of governmental organization is present (e.g. city, county government, planning offices).

Industry/Business A for-profit entity.

Faith-Based Organization based on religion or a religious group, OR faithbased organizations that are rooted in a particular faith carrying out programs and services related to that faith. 
COMMUNITY-ACADEMIC PARTNERSHIPS IN THE COMMUNITY ENGAGEMENT

LITERATURE: A SCOPING REVIEW

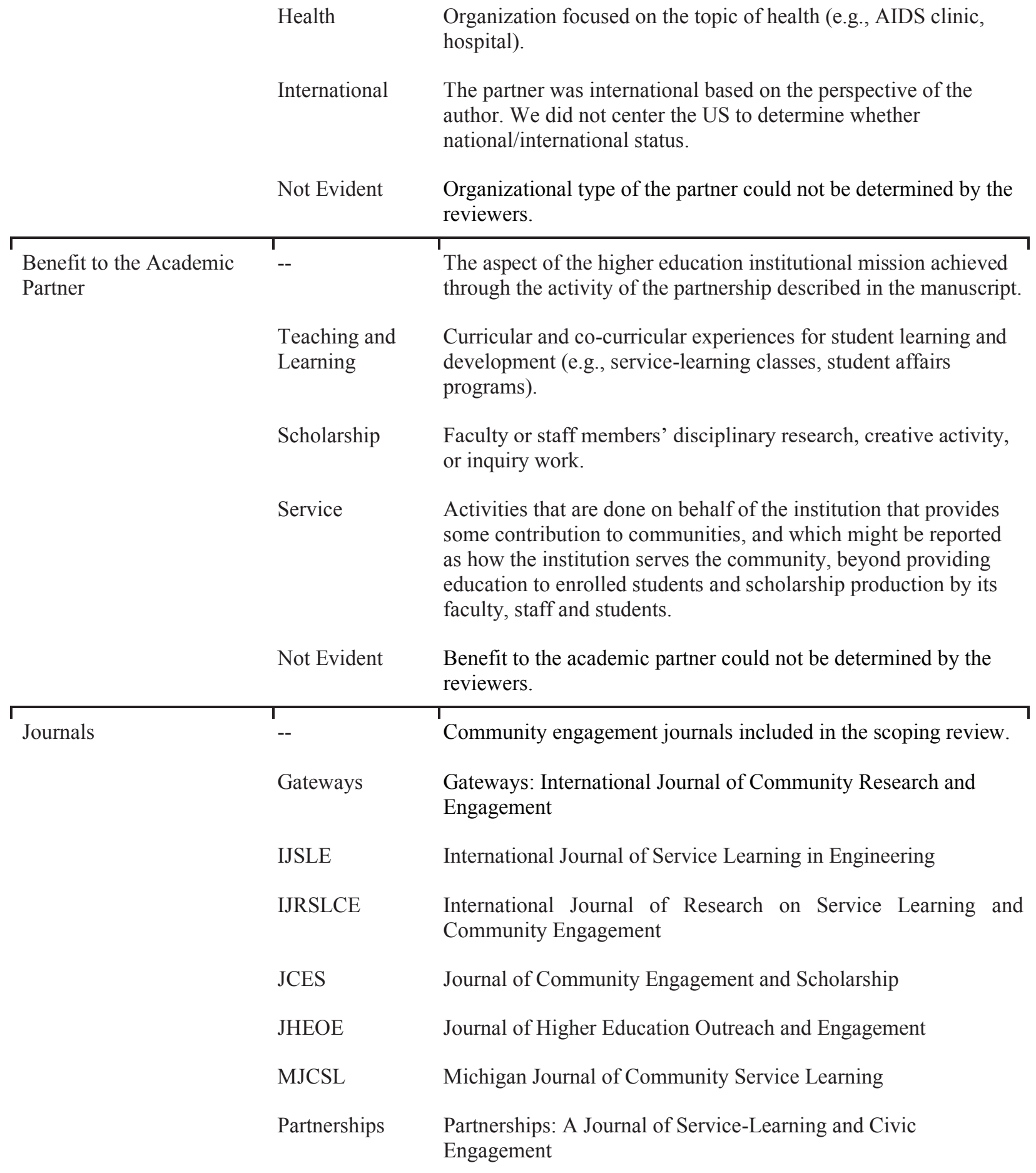

\section{Data Availability}

All data used for this study are available in Janke, Santos and Edwards (2021) via CivicLEADS (Civic Learning, Engagement, and Action Data Sharing). CivicLEADS provides 
COMMUNITY-ACADEMIC PARTNERSHIPS IN THE COMMUNITY ENGAGEMENT

LITERATURE: A SCOPING REVIEW

infrastructure for researchers to share and access high-quality datasets which can be used to study civic education and involvement.

\section{Positionality Statements}

Sharing the reviewers' positionalities in the context of a scoping review helps to situate the reviewers' perspectives in relation to the aim of the scoping review as well as the parameters and definitions of the categories developed. Positionality statements are not currently part of the scoping review protocol but a practice inserted by the authors. As we share later, we learned that our different roles and experiences led us to interpret some categories differently. As a result of this discovery, we collectively clarified our parameters and definitions and created a code book as a reference tool to ensure we did not drift in our interpretations. The codebook also helps make the analysis transparent and explicit enough to allow others to evaluate and build upon.

Janke is an associate professor at the University of North Carolina at Greensboro (UNCG) in the Peace and Conflict Studies Department and the director of the Institute for Community and Economic Engagement located in the division of research and focused on supporting community-engaged scholars and scholarship. She identifies as a white woman, scholar-administrator who uses and contributes to theory, scholarly practice, and administrative strategies to advocate for and support mutually beneficial and reciprocal partnerships, and community-engaged scholarship as a valued and rewarded aspect of academic work. Janke serves on the editorial boards and as a reviewer for several of the community engagement journals included in this study and is a member of the Carnegie Foundation's Community Engagement Elective Classification National Advisory Committee.

Flores holds a master's degree in peace and conflict studies and is currently pursuing a doctorate of philosophy in kinesiology, both at UNCG. He identifies as queer ("politically and 
COMMUNITY-ACADEMIC PARTNERSHIPS IN THE COMMUNITY ENGAGEMENT

LITERATURE: A SCOPING REVIEW

poetically"(Wallace, 2021)), latinx, black-indigenous feminist, male, activist academic,

community member and advocate, peace and conflict scholar, capoeira coach, educator and very

disruptive student. He is interested in community and youth development, critical theory, cultural

studies and practices that enhance social justice mindfulness, embodiment, and critical

consciousness. Flores leads multiple community-engaged projects, which use popular education, cultural organizing, and critical pedagogy.

Edwards has been a community partner, educator, staff member, and student within various community engagement projects, so she tries to draw on those differing perspectives in her current work and scholarship. As a white woman who studies social justice issues, she highly values co-created and participatory approaches to community engagement work. She understands and enacts research from a critical paradigm and is thus concerned with how community-academic partnerships can disrupt or uphold forms of power, privilege, and oppression.

\section{Descriptive Overview of the Articles}

The "data charting" process provides a descriptive summary of the results that aligns with the objectives and questions of the scoping review. Given the goals of transparency and reproducibility, clarity with regards to the methods used to chart the data is paramount. It is recommended that in determining the categories and characteristics used to describe the articles reviewers use an iterative process. The codebook provided in Table 1 provides the reader with the definition and description of the data charting process - the categories and characteristics used to analyze each article included in this scoping review. Table 2 provides the results of our data charting. 
COMMUNITY-ACADEMIC PARTNERSHIPS IN THE COMMUNITY ENGAGEMENT

LITERATURE: A SCOPING REVIEW

Table 2. Categories and Characteristics of Scoping Review Journal Articles

\begin{tabular}{|c|c|c|c|c|}
\hline Category & Characteristic & Total & $\begin{array}{l}\% \text { of All } \\
\text { Articles } \\
(\mathrm{N} / 141)\end{array}$ & $\begin{array}{l}\mathrm{N} / \mathrm{X} \\
=\text { Category } \\
\text { Totals }\end{array}$ \\
\hline & 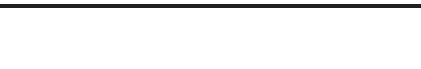 & $\mathrm{N}$ & $\%$ & $\%$ \\
\hline \multirow[t]{3}{*}{ Date Published } & $2011-2020$ & 98 & $70 \%$ & $\mathrm{n} / \mathrm{a}$ \\
\hline & 2001-2010 & 40 & $28 \%$ & $\mathrm{n} / \mathrm{a}$ \\
\hline & 1994-2000 & 3 & $2 \%$ & $\mathrm{n} / \mathrm{a}$ \\
\hline \multirow{2}{*}{$\begin{array}{l}\text { Source of Partnership } \\
\text { Information }\end{array}$} & Actual & 114 & $81 \%$ & $\mathrm{n} / \mathrm{a}$ \\
\hline & Idea & 27 & $19 \%$ & $\mathrm{n} / \mathrm{a}$ \\
\hline \multirow[t]{7}{*}{ Authors' Scholarly Approach } & Qualitative & 74 & $52 \%$ & $\mathrm{n} / \mathrm{a}$ \\
\hline & Project/Program Description & 29 & $21 \%$ & $\mathrm{n} / \mathrm{a}$ \\
\hline & Conceptual & 19 & $13 \%$ & $\mathrm{n} / \mathrm{a}$ \\
\hline & Mixed Methods & 6 & $4 \%$ & $\mathrm{n} / \mathrm{a}$ \\
\hline & Indigenous or Decolonial & 6 & $4 \%$ & $\mathrm{n} / \mathrm{a}$ \\
\hline & Program Evaluation & 4 & $3 \%$ & $\mathrm{n} / \mathrm{a}$ \\
\hline & Quantitative & 3 & $2 \%$ & $\mathrm{n} / \mathrm{a}$ \\
\hline \multirow[t]{3}{*}{ Author's Positionality } & Direct & 82 & $58 \%$ & $\mathrm{n} / \mathrm{a}$ \\
\hline & Indirect & 49 & $35 \%$ & $\mathrm{n} / \mathrm{a}$ \\
\hline & N/A, not evident & 10 & $7 \%$ & $\mathrm{n} / \mathrm{a}$ \\
\hline \multirow[t]{4}{*}{ Community Partners' Voices } & Not evident & 87 & $62 \%$ & $\mathrm{n} / \mathrm{a}$ \\
\hline & Yes: Total & 54 & $38 \%$ & $\mathrm{n} / \mathrm{a}$ \\
\hline & -Direct Quotes & 34 & $24 \%$ & $\mathrm{n} / \mathrm{a}$ \\
\hline & -Co-authored & 20 & $14 \%$ & $\mathrm{n} / \mathrm{a}$ \\
\hline \multirow[t]{3}{*}{ Partner Organizational Type } & Non-Profit & 70 & $50 \%$ & $24 \%$ \\
\hline & K-12 Education & 39 & $28 \%$ & $13 \%$ \\
\hline & Government & 34 & $24 \%$ & $12 \%$ \\
\hline
\end{tabular}


COMMUNITY-ACADEMIC PARTNERSHIPS IN THE COMMUNITY ENGAGEMENT

LITERATURE: A SCOPING REVIEW

\begin{tabular}{|c|c|c|c|c|}
\hline & Faith-Based & 30 & $21 \%$ & $10 \%$ \\
\hline & Informal Organization & 28 & $20 \%$ & $10 \%$ \\
\hline & Not Evident & 25 & $18 \%$ & $9 \%$ \\
\hline & Industry/Business & 22 & $16 \%$ & $8 \%$ \\
\hline & Health & 22 & $16 \%$ & $8 \%$ \\
\hline & International & 20 & $14 \%$ & $7 \%$ \\
\hline \multirow[t]{4}{*}{ Benefit to Academic Partner ${ }^{b}$} & Teaching and Learning & 80 & $57 \%$ & $42 \%$ \\
\hline & Scholarship & 49 & $35 \%$ & $26 \%$ \\
\hline & Service & 47 & $33 \%$ & $25 \%$ \\
\hline & Not Evident & 15 & $11 \%$ & $8 \%$ \\
\hline \multirow[t]{7}{*}{ Journal } & $\begin{array}{l}\text { Journal of Higher Education Outreach and } \\
\text { Engagement (1996) }\end{array}$ & 36 & $26 \%$ & $\mathrm{n} / \mathrm{a}$ \\
\hline & $\begin{array}{l}\text { Journal of Community Engagement and } \\
\text { Scholarship (2008) }\end{array}$ & 28 & $20 \%$ & $\mathrm{n} / \mathrm{a}$ \\
\hline & $\begin{array}{l}\text { Michigan Journal of Community Service } \\
\text { Learning (1994) }\end{array}$ & 24 & $17 \%$ & $\mathrm{n} / \mathrm{a}$ \\
\hline & $\begin{array}{l}\text { Partnerships: A Journal of Service- } \\
\text { Learning and Civic Engagement (2009) }\end{array}$ & 18 & $13 \%$ & $\mathrm{n} / \mathrm{a}$ \\
\hline & $\begin{array}{l}\text { International Journal of Service Learning in } \\
\text { Engineering (2006) }\end{array}$ & 15 & $11 \%$ & $\mathrm{n} / \mathrm{a}$ \\
\hline & $\begin{array}{l}\text { International Journal of Research on } \\
\text { Service Learning and Community } \\
\text { Engagement (2013) }\end{array}$ & 14 & $10 \%$ & $\mathrm{n} / \mathrm{a}$ \\
\hline & $\begin{array}{l}\text { Gateways: International Journal of } \\
\text { Community Research and Engagement } \\
\text { (2008) }\end{array}$ & 6 & $4 \%$ & $\mathrm{n} / \mathrm{a}$ \\
\hline
\end{tabular}

Note. Any category with an asterisk denotes a single-choice decision regarding that characteristic. Otherwise, multiple characteristics could be applied to the category.

${ }^{a}$ Partner Organizational Category total $=290$

${ }^{\mathrm{b}}$ Benefit to Academic Partner Category total $=191$

While a best practice in scoping reviews is to present the findings without additional explanation, we deviate from that recommendation. Our reasoning for this decision is based on 
COMMUNITY-ACADEMIC PARTNERSHIPS IN THE COMMUNITY ENGAGEMENT

LITERATURE: A SCOPING REVIEW

one of the purposes of the article — to make the process transparent for purposes of learning new

methods. We also include future areas of research for each category.

\section{Time Period}

How has the volume of scholarship on community engagement partnership changed since the first journals of the field were published? We categorized articles into three time periods: 1994-2000, 2000-2010, and 2011-2020. We selected 1994 as the start for the first time period because it is when the first journal was published. The percentage has grown significantly across time periods with just three articles (2\%) published in the first five years, 40 articles $(28 \%)$ published between 2001 and 2010, and 98 articles (70\%) published between 2011 through May 2020.

Analysis across these time periods show that partnerships have gained increased attention. In this way, it appears that scholars have, to some extent, responded to calls for increased attention to partnerships. The increase in partnership studies may be, in part, a result of the emergence of new journals. In the first time period (1994-2000), just two of the seven journals in this scoping review were launched (MJCSL 1994, JHEOE 1996), while four were added by the end of the second time period (IJSLE 2006, Gateways 2008, JCES 2008, Partnerships 2009), and the final one was added in the third (IJRSLCE 2013).

Future research might investigate how the partnership literature has changed over time with regards to topics, scholarly approaches, and authorship. For example, how has partnership scholarship increased relative to other topics? In what ways has theoretical grounding or empirical evidence grown over time? Most of the journals have transitioned from early paywalls to access articles to an open access model. How, if at all, has moving from print to online, and from subscription to open access, corresponded to changes in the number of articles written on 
COMMUNITY-ACADEMIC PARTNERSHIPS IN THE COMMUNITY ENGAGEMENT

LITERATURE: A SCOPING REVIEW

the topic within as well as across journals? For example, moving away from print may have allowed some journals to publish more frequent volumes and with greater numbers of articles in each.

\section{Source of Partnership Information}

Sometimes, authors write about a particular partnership, while other times they write about partnerships more abstractly and without reference to any specific one. The large majority of articles $(81 \%)$ were based on the author's examination of specific partnerships, while approximately a fifth (19\%) of the articles were written about the topic of partnerships without referencing any singular partnership. Practically speaking, researchers looking for empirical evidence, or ideas grounded in direct observations, need to be able to cull these articles from ones that are based more relatively on abstraction. Future research might use this data set as a starting point to select articles for a meta-analysis or meta-review of findings developed from studies on partnerships.

\section{Authors' Scholarly Approaches}

We examined the authors' approaches used to develop a scholarly understanding of the topic presented in the manuscript. The overwhelming majority of articles used qualitative research methods $(52 \%)$, followed by program or project descriptions $(21 \%)$, and conceptual inquiry approaches (13\%). Very few articles presented mixed methods research (4\%), Indigenous or decolonial approaches (4\%), program evaluation (3\%), and quantitative research $(2 \%)$.

It is important to note that the authors' scholarly approaches are separate and may be different from the scholarly approaches used by participants who may have been the focus of the study. For example, the author may have used a qualitative case study design to examine the 
COMMUNITY-ACADEMIC PARTNERSHIPS IN THE COMMUNITY ENGAGEMENT

LITERATURE: A SCOPING REVIEW

partnership facilitating a service-learning course or a course-based, undergraduate research

project. So, while the scholarly approach of the faculty member may have been a mixed methods

research project, the authors of the article used a qualitative approach in their study of that undergraduate research project.

While it is best practice for scoping reviews to choose categories that are mutually exclusive (i.e., a study can only be coded into one category), we found that, with regard to scholarly approaches, this was difficult to do in many cases. As we discuss later, the development of this category was challenging given (a) inconsistent definitions of the approaches among scholars generally, and (b) the imprecise and sometimes entirely absent discussion of methodological approaches offered by authors. Ultimately, the development of the categories, and the assignment of the articles to the categories in particular, often felt like a subjective effort as we looked for and interpreted methods and strategies based on textual clues rather than explicit statements regarding approach. When authors' did name their approach to the research (e.g., This is a case study about...), we respected that naming even if it did not fit with accepted research definitions. Ultimately, through an iterative process of reading manuscripts and reviewing and revising the characteristics and the descriptions of the characteristics, we selected the seven categories to describe the scholarly approaches used by the authors of the manuscripts included in this review.

Given the challenges of studying partnerships due to the varied nature of the partners, their activities, purposes, contexts in which they work, and whether the relationships occur at an interpersonal or inter-institutional level (Janke, 2012), it is helpful to scan articles to understand the research approaches used so others may build upon and refine these approaches for their own studies. Categorizing by scholarly approaches allows one to map the ways that the authors' 
COMMUNITY-ACADEMIC PARTNERSHIPS IN THE COMMUNITY ENGAGEMENT

LITERATURE: A SCOPING REVIEW

approached their exploration of partnerships, which is helpful for understanding the types of "evidence" (e.g., qualitative, quantitative) brought to bear on the topic. What, if any, research questions were asked, what methodologies and methods were used, how did the scholar decide who to include in their interviews, what artifacts were used, what compromises were made given the challenges? Future research might examine the ways that scholarly approaches tend to align to certain disciplines, partnerships, or expected outcomes for the community engagement activity. Future scoping reviews might chart the methods used within each of the approaches.

\section{Authors' Positionality Relative to the Partnership}

In articles in which the author described an actual partnership, we sought to understand the relationship of the authors to that partnership. We wanted to know: To what extent does the literature represent perspectives of those on the "inside" relative to those "outside" the partnership? Over half (58\%) of the articles were authored by members of the partnerships; that is, the author appeared to play a partner role in the community-academic partnership described in the article. Approximately one-third of the articles (35\%) were authored by scholars not involved in the partnership. In some instances (7\%), it was not possible to determine the authors' positionality, or the manuscript was written as a thought piece in which there was no actual partnership being described.

The relationship of an author to their area or focus of study can be framed either as an asset or a limitation depending on a reader's own research paradigm (Glesne, 2016). Having “insider" status and knowledge may be advantageous in that it allows for access, perspectives, and insights of the partnership that might not otherwise be available. In Indigenous or decolonial approaches, it is, indeed, an essential requirement as knowledge is generated and stewarded by and through the relationships of the people holding and sharing the knowledge (Kovach, 2009; 
COMMUNITY-ACADEMIC PARTNERSHIPS IN THE COMMUNITY ENGAGEMENT

LITERATURE: A SCOPING REVIEW

Smith, 2012). In some views and instances, however, relational closeness can be viewed as a

limitation. How does the author's positionality affect what and how they view and experience the partnership? What is the level of comfort and trust among the author and the partners or participants involved in the study; might they not disclose ideas or issues for the sake of the relationship (or lack thereof) with the author? Depending on the scholarly approach and topic, positionality may matter a great deal. Future research might examine, how, if at all, the authors' positionality relative to the partnership corresponds with types of scholarly approaches used, the topics pursued, or the outcomes assessed.

\section{Presence of Community Partners' Voices in the Text}

Initial coding revealed different ways that the ideas of community partners (i.e., individuals who are actively contributing to the partnership work, but who do this work outside of academic positions) were included in the manuscript. Through an iterative process among the three reviewers, we examined the presence of community partners' voices as represented by their co-authorship of the article, or by direct quotes of their spoken words or writings. The presence of community voice, either via co-authorship or direct quotes, was not evident in approximately $62 \%$ percent of the articles. Approximately, $14 \%$ percent of the articles had community partners as co-authors (which may or may not have also included direct quotes from them or other community partners), and 24\% percent of the articles included direct quotes of community partners (and no co-authorship).

Knowing whether an article includes community partner co-authorship can, for example, be helpful for research that seeks to understand the contributions of community partner writing to academic literature. Knowing the extent to which manuscripts include the expressed words of community partners is helpful for those who wish to, for example, use discourse analysis to 
COMMUNITY-ACADEMIC PARTNERSHIPS IN THE COMMUNITY ENGAGEMENT

LITERATURE: A SCOPING REVIEW

examine the ways in which community partners express their experiences. Scholars working in community-academic writing teams might review co-authored articles for ideas on how to frame their own research and scholarly writing. Future action research might explore barriers to community co-authorship; rationale for what we term lack of community presence in community engagement literature; and advocate for pathways for voices and authorship by those actively contributing to the partnership work, but who do this work outside of academic positions.

\section{Community Partner Organizational Type}

Faculty, staff and students may partner with individuals who represent different types of formal and informal organizations. Organizations have different organizational missions, structures, and cultures, which meaningfully affect how their members do their work. Navigating a partnership with a K-12 school, for example, can be very different in terms of partner's expectations for how (e.g., policies), where (e.g., multi- or specific-use spaces and resources), and when (e.g., school day, evening, weekends) to work together compared to navigating a partnership with an informal community group. When examining the structures, processes, and findings related to community-academic partnerships, it is important to understand this organizational context.

This scoping review shows the range of community partners' organizational setting. We assigned all organizational types mentioned in an article (see Appendix for actual counts) and found that across all articles, nonprofits were the most represented type (found in $50 \%$ of all articles, and $24 \%$ of all partner organizational types recorded). Approximately a fifth to a quarter of the articles involved $\mathrm{K}-12$ schools, government, faith-based, informal organization and businesses/industry. The fewest articles included international and healthcare organizations. Notably, reviewers were unable to assign an organizational type to 25 of the 141 articles (18\%) 
COMMUNITY-ACADEMIC PARTNERSHIPS IN THE COMMUNITY ENGAGEMENT

LITERATURE: A SCOPING REVIEW

due to lack of specific partnership information provided by the authors. Future research and analyses might explore differences within and among partnerships based on the organizational type of the community partners, or why some organizational types are more represented than others.

\section{Benefit to the Academic Partner}

Whether the academic partner is collaborating as a function of their teaching, research, or service roles likely shapes key aspects of their collaborative work, such as their purposes, processes, timelines, and resources, among others. From the perspective of the academic partner, we coded for what aspects of the institutional mission appear to be achieved through the activity of the partnership described in the manuscript. The majority of articles (57\%), described partnerships in which academic partnerships were engaging students through a course (teaching and learning), while over a third (33\%) appeared to be offering service not connected to teaching or research. Approximately a third (35\%) of articles involved the academic partners' research or scholarship activity. Not enough information was evident in approximately $11 \%$ of the articles to determine the role of the academic partner in the partnership. Future research might explore the broad range of benefits to the community partner, the methods the university uses to engage in pedagogy and learning, and institutional motivations for service and scholarship.

\section{Analysis: A Discussion of Findings and Process}

For many scoping reviews, simple frequency counts of concepts, populations, characteristics or other fields of data will be all that is required (JBI, 2015). As JBI notes, "Qualitative content analysis in scoping reviews is generally descriptive in nature and reviewers should not undertake thematic analysis/synthesis" (11.2.8). Thematic analysis may be taken up separately, and often guided by a research question, such as "How does the publication record 
COMMUNITY-ACADEMIC PARTNERSHIPS IN THE COMMUNITY ENGAGEMENT

LITERATURE: A SCOPING REVIEW

vary according to the journal?" Or, "In what ways, if at all, are articles which are co-authored by community partners more likely to describe community perspectives of the partnership than those authored by academic partners alone?" Or, even more broadly, "How have research questions and methodologies evolved since the beginning of the publication record in the community engagement field?" However, such analysis of the within-article content is beyond the scope of a scoping review, including this one. The contribution provided by this scoping review is the curation of the broad field of evidence (i.e., the partnership article dataset), and the identification and description of key characteristics of that literature at the article level.

At the same time, there are good reasons to incorporate some analysis in this article, especially related to our experiences of conducting the scoping review. Since scoping reviews are a new method to community engagement, analyzing our process may offer lessons to scholars who will consider this method in their future work, including, we hope, expansion and refinement of this scoping review. In this section we analyze our experience in conducting a scoping review of the community engagement literature, which is, in many ways, quite different from the literature found in the health professions out of which the scoping review protocols have been developed and refined. We discuss the challenges in conducting this scoping review, as well as the opportunities we see for scoping reviews in the community engagement field.

\section{Principles and Values as Core Aspects of Community Engagement Literature}

We intended to develop understanding about particular types of community-academic partnerships, one that would meet the criteria for community engagement, as defined by scholars in the community engagement field. Demarcating community engagement partnerships, as defined by the Carnegie Foundation, from other forms of place-based or community-academic partnerships, such as internships, clinicals, teacher placements, and outreach and extension 
COMMUNITY-ACADEMIC PARTNERSHIPS IN THE COMMUNITY ENGAGEMENT

LITERATURE: A SCOPING REVIEW

relationships is critical to the further development and future maturation of the community engagement field. To the extent possible, we hoped to limit our review to those meeting the definition of community engagement as defined by the Carnegie Foundation. This definition is similar to other definitions that describe community engagement not only by who (communities and academic partners), but also according to process (reciprocity) and outcome (mutual benefit) (see Saltmarsh et al., 2009). This finding is also evident in the scoping review of conceptions of community engagement conducted by Beaulieu et al. (2018).

However, how does one determine accurately and with confidence that the article they choose to include in their scoping review meets the criteria of a community engagement partnership as defined by the community engagement field? Many institutions and journals use a variety of terms to describe partnerships that might be considered for inclusion. For example, scholars in physical education refer to partnerships that meet our established criteria as "servicebonded inquiry" (Martinek et al., 2012), while other fields use terms such as public scholarship (Colbeck \& Wharton-Michael, 2006). One might look beyond the term to identify criteria for identifying articles. According to the Carnegie definition used here, one could look for indicators of reciprocity and mutual benefit among community and academic partners (Janke, Shelton, Norris \& Medlin, 2019). However, given the limited information often provided about the process and outcomes of partnerships (let alone the partners themselves!), this does not seem a feasible approach. Further, is it possible — or even appropriate-for a researcher who has no direct knowledge of the partnership to make this determination based on the contents of the written word? How do you make this determination if the process or outcomes are not clearly stated? 
COMMUNITY-ACADEMIC PARTNERSHIPS IN THE COMMUNITY ENGAGEMENT LITERATURE: A SCOPING REVIEW

In an effort to manage the unwieldy and fraught task of determining whether a single article met this criterion for inclusion (i.e., community-engaged, community-academic partnerships), we chose to screen articles based on the publication (i.e., journal) rather than to establish criterion at the article level. This is a limitation of our scoping review. As community engagement becomes more accepted as a research methodology or pedagogy, more community engagement articles are likely to be published in disciplinary journals. In fact, we note on the Campus Compact Partnerships Knowledge Hub the inclusion of articles published in journals outside the community engagement field. A strategy to conduct a scoping review of communityengaged, community-academic partnership across disciplines remains to be developed.

\section{Variability of Scholarly Approaches and Presentation of Works}

Per scoping review protocol, we followed an a priori process in which we identified our guiding question and established a protocol for identifying articles. However, the process for establishing, refining, and finalizing categories and codes was deeply iterative and extended throughout the study. The continuously iterative process was necessary, in part, because of the nuances of the concepts related to community-engaged, community-academic partnerships but also because there are few common conventions for authors to describe the who, what, where, when, why, and how as it relates to community engagement partnerships. Who was involved in the partnership and what were their roles? What groups or organizations were partners' acting on behalf of? Where are partnerships occurring and what are the institutional affiliations of the authors? Why or through what work role is the academic partner representing their organization, teaching, research, and/or service? How is the author related to the partnership being described?

Because we were interested in understanding the scope of evidence in the field that has been brought to bear in the literature as it relates to community-academic partnerships, we tried 
COMMUNITY-ACADEMIC PARTNERSHIPS IN THE COMMUNITY ENGAGEMENT

LITERATURE: A SCOPING REVIEW

to track the methodology and methods used by the authors of the articles. This proved to be much more challenging than anticipated. The first challenge was that numerous articles did not present a methods section or did not clearly state the methodology guiding their research. While some articles briefly identified their method, case study for example, this naming was more colloquial and less about reflecting a trustworthy expression of true case study methods. This was reinforced by the absence of a conceptual or theoretical framework in those articles as well.

In reviewing these articles with no methodological or theoretical discussion, we came to conclude that we needed to differentiate among subsets of articles: (a) those that describe programs but are not considered to be research (project description), (b) those that ask research questions that are addressed using qualitative methods (qualitative research), (c) and those that conceptually explore a topic or put forth an argument using existing literature, rather than one's own analysis of a partnership (conceptual scholarship).

It was not always easy to establish which articles used qualitative research approaches given the varying and limited descriptions of methodologies and methods used. We used various indicators to make judgements such as whether an author used certain methods or terms typically reflective of a scholarly approach. For example, qualitative scholarship was judged on the presence of references to a research question, theoretical or conceptual framework, the use of the term "case study," or qualitative methods such as observations, interviews, document, or textual analysis.

A notable subset of the articles was primarily descriptive: The authors intended to share their experience of partnering and sometimes shared lessons learned based on their reflections on their experiences, but they did not attempt to develop generalizable knowledge that could be 
COMMUNITY-ACADEMIC PARTNERSHIPS IN THE COMMUNITY ENGAGEMENT

LITERATURE: A SCOPING REVIEW

extended to other partnerships as is the purpose of other forms of research. We labeled these as program descriptions.

Ultimately, the final decisions made about the characterizations of many articles felt uneasy due to the lack of evidence to support our judgments. In these cases, in which we were very uncertain, we created and used categories that suggested not enough evidence was available, recognizing that a lack of evidence in the written word does not mean it was not present in the actual partnership.

Through an iterative process of reviewing the articles and revisiting our guiding question, we modified the labels of our categories and characteristics to best reflect our analyses. For example, we changed the category label from methodology to scholarly approaches to more accurately recognize the diverse approaches describing and examining partnerships — some of which constituted research, much of which did not. We settled on these final categories: qualitative research, quantitative research, mixed methods research, Indigenous or decolonial scholarship, program evaluation, project description, and conceptual scholarship/inquiry.

\section{Positionality}

The positionality of each reviewer became evident in the assumptions we made both in the development of the categories, as well as the characteristics developed. For example, in the first iteration, the first author created the category, "type of activity through which the partners are interacting: research, teaching, creative activity, or service." Her scholarship on promotion and tenure and institutional change from a higher education perspective had grounded the idea that the important thing to map was the type of academic role through which the academic partners were engaged. The second and third authors, having their own community perspectives from their roles as community partners currently or previously, questioned the name and 
COMMUNITY-ACADEMIC PARTNERSHIPS IN THE COMMUNITY ENGAGEMENT

LITERATURE: A SCOPING REVIEW

description of the category. They offered that this perspective was slanted entirely towards the role of the academic partners (what "hat" was the academic faculty or staff member wear in the partnership) but did not include the community partners. We decided to rename the category, "benefit to the academic partner" to more accurately name what it was we were actually mapping in this category. That is, there were no characteristics within the category that described the role through which the community partner was engaged, such as through running programs, services, coordinating volunteers, or some other role.

Other instances in which we observed our positions and/or frames were that we did not include categories for institutional types of the higher education partner, such as whether they represented a public or private institution, were 2- or 4-year institutions, or were located in an urban or rural environment, to name a few. We did not seek to describe the position or rank of the academic partners, and we did not track student roles or engagement, such as co-authors, other than noting whether partnerships were connected to partners' teaching roles. Scholars embedded in land grant institutions and in outreach and extension offices, or those with economic engagement and community development, or in student affairs units would have brought their own lenses with regards to what aspects of the partnership literature were most important to collect.

Positionality is present in any and all scholarship — who we are frames what we look for, what we see, and how we see things. In a number of articles included in this scoping review, it was difficult to determine the presence of community voice, or the relationship of the author to the partnership being described. Clear positionality statements would remedy this obfuscation. 
COMMUNITY-ACADEMIC PARTNERSHIPS IN THE COMMUNITY ENGAGEMENT

LITERATURE: A SCOPING REVIEW

\section{Setting Parameters}

We made choices about the sources and types of scholarly products to include in this scoping review based on the goals of the review, and also necessarily shaped by feasibility and capacity of the researchers. Our goal broadly was to gain a sense of the community-academic partnership landscape as it relates to what has been published on the topic. Even broader, our goal was to develop a scoping strategy for community engagement literature as a contribution to the field given that it is among the first of its kind (see also Beaulieu et al., 2018).

This scoping review maps articles from seven journals that were available in English, accessible online, and included in lists of community engagement journals commonly listed or hosted by community engagement associations in the United States. Gateways was the only journal that purposefully features studies authored by scholars outside of the United States (US), and primarily in Australia (many of the editors and associate editors are from Australian universities though the journal is hosted in the US). With only a few exceptions, the manuscripts that include international partnerships, depict the perspectives of US-affiliated faculty, staff, and students traveling abroad to work with partners from other countries. In this way, the map we provide is situated within the US perspective of academic partners either partnering with communities also in the US, or with partners from other countries. There are only a few studies in which the academic partners are from outside of the US working with partners who are also outside of the US, such as in their home country. We would also like to see the inclusion of additional journals that likely have much to offer by way of community engagement partnerships (e.g., Public, Metropolitan Universities Journal, eJournal of Public Affairs, and Journal of Community Engagement and Higher Education) and which were not included due to extensive time and resources required for this level of scoping review. 
COMMUNITY-ACADEMIC PARTNERSHIPS IN THE COMMUNITY ENGAGEMENT

LITERATURE: A SCOPING REVIEW

\section{Summary}

Scoping reviews are relatively new approaches to mapping the existing literature in a field of interest in terms of the volume, nature, and characteristics of the primary research (Arksey \& O'Malley, 2005). Scoping reviews are different from other types of reviews, such as more commonly used literature reviews and systematic analyses. Their aim and purpose is to map the body of work available on a topic in a field, whereas a literature review selectively presents the scholarship most relevant to a research question, and a systematic review attempts to distill from extant literature the best available research on a specific question. In this sense, their findings stand alone as important contributions to the field, as well as provide a robust foundation for future research and inquiry.

The information brought to light via a scoping review can be quite evocative even though it follows a prescriptive process. The review process of articles wherein researchers identify and map key characteristics of the literature serves as a catalyst to see new ideas and spark new questions. So while analysis of content is limited in a scoping review, it serves as an invitation to imagine new research questions. Ultimately, this scoping review provides not only a view of the scholarly literature on community-academic partnerships, but it also provides important insights and directions for future scoping studies within the field of community engagement.

Sharing existing datasets, such as the compendium of articles that have been identified, catalogued, and categorized according to meaningful attributes (e.g., partner type, activity, voice) can lessen the barrier for future scholars who wish to conduct a comprehensive literature review for their research on a particular sub-topic within the community-academic partnership literature (e.g., conflict management). A compendium is also invaluable to scholars who do not have access to journals behind paywalls. A scoping review, done in advance of a systematic review, 
COMMUNITY-ACADEMIC PARTNERSHIPS IN THE COMMUNITY ENGAGEMENT

LITERATURE: A SCOPING REVIEW

provides authors with a "map" of the "literature landscape," which allows them to refine their selection of articles for inclusion in their own study. Once the articles have been fully curated, sorted, and described according to key characteristics, one can choose among them to determine relevant articles. This is a key contribution of this work.

This scoping review of the community-academic partnership in the community engagement literature is the first of its kind and provides both a transparent description of the methods used to conduct a scoping review, and it also provides key descriptive statistics mapping the breadth and depth of the field along key categories. We identified eight mapping categories, creating a code book, data displays that show how each article was mapped, and a full reference list of articles included in our scoping review. In reviewing the articles, the team identified many challenges in accurately assessing key characteristics of the scholarship, such as the scholarly approach, or methodology the authors were using to study partnerships, as well as the organizational type of the community partners. We believe that this scoping review can serve as encouragement, instruction, and a potential source of data for future scoping reviews and other forms of research.

\section{Acknowledgements}

We extend our thanks to Dr. Michael Hemphill who provided important encouragement and feedback on our scoping review process and our manuscript, and to Dr. Rebecca Dumlao, Jayke Hamill, Dr. Lynda Kellam, and Yashika Johnson, for their early efforts and lessons that helped us to establish protocols for finding and sorting partnership articles across databases and systems. 
COMMUNITY-ACADEMIC PARTNERSHIPS IN THE COMMUNITY ENGAGEMENT

LITERATURE: A SCOPING REVIEW

\section{References}

NOTE: We include only references in our article, not the articles scoped per Ch. 11 "Scoping Reviews" in the JBI Manual of Evidence Synthesis,

https://wiki.joannabriggs.org/display/MANUAL/Chapter+11\%3A+Scoping+reviews

Arksey, H., \& O’Malley, L. (2005). Scoping studies: Towards a methodological framework. International Journal of Social Research Methodology, 8(1), 19-32. DOI: $\underline{10.1080 / 1364557032000119616}$

Janke, E. (2012). Organizational partnerships in service learning: Advancing theory-based research. In P. H. Clayton, R. G. Bringle, \& J. A. Hatcher (Eds.), Research and service learning: Conceptual frameworks and assessment (Vol. 2B, pp. 573-598). Stylus.

Janke, E., \& Dumlao, R. (2019). Developing communication repertoires to address conflict in community engagement work. Journal of Higher Education Outreach and Engagement, 23(1), 35-56.

Janke, E., Shelton, T., Norris, K., \& Medlin, K. (2019, October). Measuring Mutual Benefit and Reciprocity in Community Engagement and Public Service Activities. International Association for Research on Service-Learning and Community Engagement Conference, Albuquerque, NM.

Beaulieu, M., Breton, M., \& Brousselle, A. (2018). Conceptualizing 20E years of engaged scholarship: A scoping review. PLoS ONE, 13(2), e0193201. https://doi.org/10.1371/journal.pone.0193201

Bloomgarden, A. (2017). Out of the armchair: About community impact. International Journal of Research on Service-learning and Community Engagement, 5(1), 21-23. 
COMMUNITY-ACADEMIC PARTNERSHIPS IN THE COMMUNITY ENGAGEMENT

LITERATURE: A SCOPING REVIEW

Bowen, G., Author Bargerstock, B., Berrien, C., Furco, A., Hurd, C., Peterson, C., \& Pearl, A. (2019, October 23-25). How to get published in service-learning and community engagement journals. Presentation at International Association for Research on ServiceLearning and Community Engagement Conference, Albuquerque, NM.

Boote, D. N., \& Beile, P. (2005). Scholars before researchers: On the centrality of the dissertation literature review in research preparation. Educational Researcher, 34(6), 315. https://doi.org/10.3102/0013189X034006003

Bringle, R. C., Clayton, P., \& Price, M. (2012). Partnerships in service learning and civic engagement. Partnerships: A Journal of Service-Learning and Civic Engagement, 1(1).

Bringle, R. G., Clayton, P. H., \& Hatcher, J. A. (2013). Research on service learning: An introduction. In R. G. Bringle, P. H. Clayton, \& J. A. Hatcher (Eds.), Research on service learning: Conceptual frameworks and assessment: Communities, institutions, and Partnerships (Vol. 2B; pp. 335-358). Stylus.

Campus Compact. (n.d.). Community partnerships knowledge hub. https://compact.org/community-partnerships/key-readings-on-campus-communitypartnerships/

Carnegie Foundation for the Advancement of Teaching. (n.d.). Defining community engagement. https://public-purpose.org/initiatives/carnegie-electiveclassifications/community-engagement-classification-u-s/

Colbeck, C. L., \& Wharton-Michael, P. (2006). Individual and organizational influences on faculty members' engagement in public scholarship. New Directions for Teaching and Learning, 2006(105), 17-26. 
COMMUNITY-ACADEMIC PARTNERSHIPS IN THE COMMUNITY ENGAGEMENT

LITERATURE: A SCOPING REVIEW

Cruz, N. I., \& Giles, D. E. (2000). Where's the community in service-learning research. Michigan Journal of Community Service Learning, 7(1), 28-34.

Dostilio, L. D. (Ed.). (2017). The community engagement professional in higher education: A competency model. Campus Compact.

Drahota, A., Meza, R. D., Brikho, B., Naaf, M., Estabillo, J. A., Gomez, E. D., Vejnoska, S.F., Dufek, S., Stahmer, A.C., \& Aarons, G. A. (2016). Community-academic partnerships: A systematic review of the state of the literature and recommendations for future research. The Milbank Quarterly, 94(1), 163-214.

Dumlao, R. J., \& Author M. (2012). Using relational dialectics to address differences in community-campus partnerships. Journal of Higher Education Outreach and Engagement, 16(2), 151-175.

Gelmon, S. B., Holland, B. A., Seifer, S. D., Shinnamon, A., \& Connors, K. (1998). Communityuniversity partnerships for mutual learning. Michigan Journal of Community Service Learning, 5, 97-107.

Giles, D. H., Jr. (2019). Seven additional years of evolution. In L. R. Sandmann \& D. O. Jones (Eds.), Building the field of higher education engagement (pp. 171-174). Stylus.

Glesne, C. (2016). Becoming qualitative researchers ( $5^{\text {th }}$ ed.). Pearson.

Hart, A., Northmore, S., Gerhardt, C., \& Rodriguez, P. (2009). Developing access between universities and local community groups: A university helpdesk in action. Journal of Higher Education Outreach and Engagement, 13(3), 45-60.

Janke, E, Flores, S, \& Edwards, K. (2021). Dataset for "Community-academic partnerships in the community engagement literature: A scoping review”. Ann Arbor, MI: Inter-university 
COMMUNITY-ACADEMIC PARTNERSHIPS IN THE COMMUNITY ENGAGEMENT

LITERATURE: A SCOPING REVIEW

Consortium for Political and Social Research [distributor].

https://doi.org/10.3886/E146781V2

Joanna Briggs Institute. (2015). Reviewers' manual 2015: Methodology for JBI scoping reviews.

Author. https://nursing.lsuhsc.edu/JBI/docs/ReviewersManuals/Scoping-.pdf

Kovach, M. (2009). Indigenous methodologies: Characteristics, conversations, and contexts. University of Toronto Press.

Kowal, M. (2017). Evolution of a profession: A review of the Community Engagement Professional in Higher Education: A Competency Model for an Emerging Field [book review]. International Journal of Research on Service-Learning and Community Engagement, 5(1), 181-183.

Levac, D., Colquhoun, H., \& O'Brien, K. K. (2010). Scoping studies: Advancing the methodology. Implementation Science, 5(1), Article 69.

Martinek, T., Hellison, D., \& Walsh, D. (2012). Service-bonded inquiry revisited: A research model for the community-engaged professor, Quest, 56(4), 397-412. DOI:

$10.1080 / 00336297.2004 .10491833$

Munn, Z., Peters, M. D., Stern, C., Tufanaru, C., McArthur, A., \& Aromataris, E. (2018). Systematic review or scoping review? Guidance for authors when choosing between a systematic or scoping review approach. BMC Medical Research Methodology, 18(1), Article 143.

Olszowy Jones, D., \& Lee, J. (2017). A decade of community engagement literature: Exploring past trends and future implications. Journal of Higher Education Outreach and Engagement, 21(3), 165-180. 
COMMUNITY-ACADEMIC PARTNERSHIPS IN THE COMMUNITY ENGAGEMENT

LITERATURE: A SCOPING REVIEW

Peters, M. D. J., Godfrey, C., McInerney, P., Munn, Z., Tricco, A.C., \& Khalil, H. (2020).

Scoping reviews. In E. Aromataris \& Z. Munn (Eds.), JBI manual for evidence synthesis (pp. 406-451). https://doi.org/10.46658/JBIMES-20-12

Pham, M. T., Rajić, A., Greig, J. D., Sargeant, J. M., Papadopoulos, A., \& McEwen, S. A. (2014). A scoping review of scoping reviews: Advancing the approach and enhancing the consistency. Research Synthesis Methods, 5(4), 371-385.

https://doi.org/10.1002/jrsm.1123

Ramaley, J. (2019). Higher education community engagement: Past, present and future. In L. R. Sandmann \& D. O. Jones (Eds.), Building the field of higher education engagement (pp. 252-263). Stylus.

Richards, K. A. R., Washburn, N., Carson, R. L., \& Hemphill, M. A. (2017). A 30-year scoping review of the physical education teacher satisfaction literature. Quest, 69(4), 494-514.

Saltmarsh, J., Hartley, M., \& Clayton, P. (2009). Democratic engagement white paper. New England Resource Center for Higher Education Publications. Paper 45. https://scholarworks.umb.edu/nerche_pubs/45

Sandmann, L. R. (2008). Conceptualization of the scholarship of engagement in higher education: A strategic review, 1996-2006. Journal of Higher Education Outreach and Engagement, 12(1), 91-104.

Sandmann, L. R., \& Jones, D. O. (Eds). (2019). Building the field of higher education engagement. Stylus.

Sandmann, L. R., Saltmarsh, J., \& O’Meara, K. (2008). An integrated model for advancing the scholarship of engagement: Creating academic homes for the engaged scholar. Journal of Higher Education Outreach and Engagement, 12(1), 47-64. 
COMMUNITY-ACADEMIC PARTNERSHIPS IN THE COMMUNITY ENGAGEMENT

LITERATURE: A SCOPING REVIEW

Shulman, L. S. (1999). Taking learning seriously. Change: The magazine of higher learning, 31(4), 10-17.

Smith, L. T. (2012). Decolonizing methodologies: Research and Indigenous peoples (2nd ed.). Zed Books.

Tricco, A. C., Lillie, E., Zarin, W., O’Brien, K., Colquhoun, H., Kastner, M., Levack, D., Ng, C., Sharpe, J. P., Wilson, K., Kenny, M. Warren, R., Wilson, C., Stelfox, H. T., \& Straus, S. E. (2016). A scoping review on the conduct and reporting of scoping reviews. BMC Medical Research Methodology, 16(1), Article 15.

Wallace, Julia “Sangodare.” (2021, June 20). Secret to my success: Mobile Homecoming Sunday Solstice Father's Day Juneteenth service [Video]. Vimeo. https://vimeo.com/565234573. 


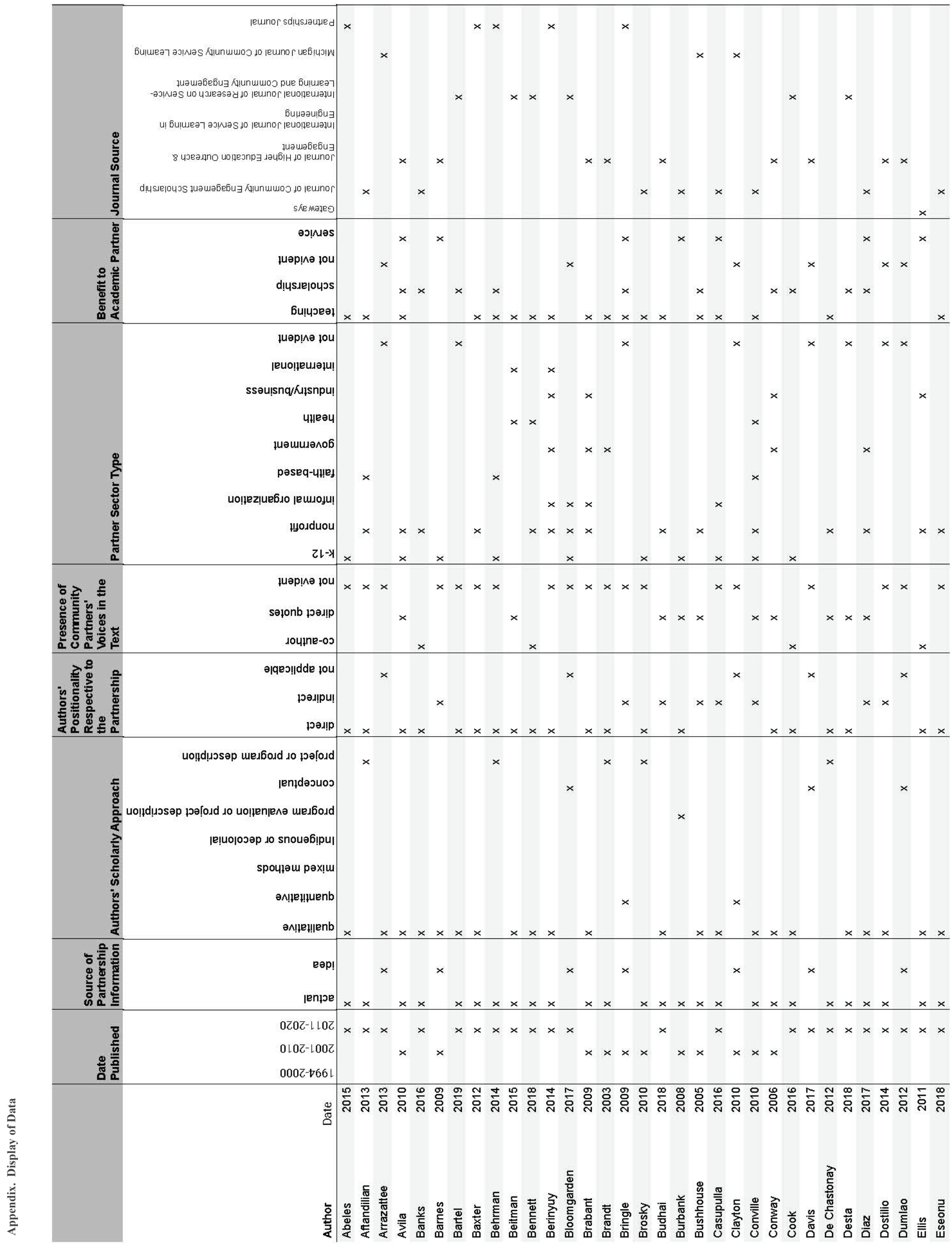





